\author{
(С) Евсеева А.Л. ${ }^{1}$ Рябова В.В. ${ }^{1}$, Кошкин С.В. ${ }^{1}{ }^{2 *}$
}

\author{
1 Кировский государственный медицинский университет \\ 610027, Россия, г. Киров, ул. К. Маркса, д. 112 \\ ${ }^{2}$ Кировский областной клинический кожно-венерологический диспансер \\ 610030, Россия, г. Киров, ул. Семашко, д. 2а
}

В статье представлен клинический случай папуло-пустулезной розацеа из собственной практики. В первую очередь интересен семейный анамнез пациента (у родного брата - эпизоды покраснения лица), дебют розацеа на фоне стрессовой ситуации, наличие заболевания желудка, связь с алиментарными факторами, в силу рода занятий отмечается периодическое употребление красного крепленого вина в небольших количествах. Одно из первых упоминаний о розовых угрях принадлежит Авиценне, который в своих трудах описывал клиническую картину ринофимы ("badschenan”, позже переименованный в “abedsamen"). Шишковидный нос, испещренный “змеевидными» сосудами, традиционно ассоциировался с неумеренным пьянством. В настоящее время роль алкоголя в качестве этиологического фрактора первостепенной не является, но доказано его усугубляющее влияние.

Несмотря на типичную картину розацеа наш пациент в течение нескольких лет неоднократно получал терапию по поводу себорейного дерматита и других заболеваний. Вероятно, у специалистов возникали сомнения о возможном диагнозе «розацеа» у пациента мужского пола в возрасте до 30 лет.

Ключевые слова: розацеа, папуло-пустулезная розацеа, триггерные факторы, изотретиноин.

Конфрликт интересов: авторы декларируют отсутствие явных и потенциальных конфрликтов интересов, связанных с публикацией настоящей статьи.

Источник фринансирования: работа выполнена и опубликована за счет фринансирования по месту работы авторов.

Согласие пациента: все пациенты добровольно подписали информированное согласие на публикацию персональной медицинской информации в обезличенной форме.

Для цитирования: Евсеева А.Л., Рябова В.В., Кошкин С.В. Клинический случай папуло-пустулезной розацеа. Вестник дерматологии и венерологии. 2021;97(3):73-79. doi: https://doi.org/10.25208/vdv1228 


\title{
$\mathrm{A}_{\text {clinical case of papulo-postulous rosacea }}$
}

\author{
(C) Anna L. Evseeva1', Vera V. Ryabova', Sergei V. Koshkin ${ }^{1,2 \star}$
}

\author{
${ }^{1}$ Kirov State Medical Academy \\ K. Marx str., 112, 610027, Kirov, Russia \\ ${ }^{2}$ Kirov Regional Clinical Skin-Venereologic Dispensary \\ Semashko str., 2a, 61030, Kirov, Russia
}

The article presents a clinical case of papulopustular rosacea from our own practice. First of all, the patient's anamnesis is extremely interesting: family history (his brother has episodes of reddening of the face), the onset of rosacea against the background of a stressful situation, the presence of gastric diseases, the connection with nutritional factors. One of the first mentions of rosacea belongs to Avicenna, who in his writings described the clinical picture of rhinophyma ("badschenan", later renamed "abedsamen"). The pineal nose, dotted with "serpentine" vessels, has traditionally been associated with excessive drinking. Currently, the role of alcohol as an etiological factor is not paramount, but its aggravating effect has been proven.

Despite the typical picture of rosacea, our patient has been receiving therapy for seborrheic dermatitis and other diseases several times over the course of several years. Probably, the specialists had doubts about the possible diagnosis of rosacea in a male patient under the age of 30 .

Keywords: rosacea, papulopustular rosacea, trigger factors, isotretinoin.

Conflict of interest: the authors declare no obvious and potential conflicts of interest related to the publication of this article.

Source of funding: the work was done and published through financing at the place of work of the authors.

Patient consent: all patients voluntarily signed an informed consent for the publication of personal medical information in anonymized form.

For citation: Evseeva AL, Ryabova VV, Koshkin SV. A clinical case of papulo-postulous rosacea. Vestnik Dermatologii i Venerologii. 2021;97(3):73-79. doi: https://doi.org/10.25208/vdv1228 
Розацеа является хроническим рецидивирующим мультифакториальным воспалительным заболеванием, которое характеризуется поражением кожи лица в виде эритемы, преимущественно в зоне иннервации тройничного нерва, последующим появлением папуло-пустулезных элементов и развитием фрим. При этом у каждого пятого пациента отмечаются проявления офтальморозацеа (окулярный подтип розацеа) с явлениями блефрарита и конъюнктивита [1, 2].

Людей с «красными носами» описывали поэты и писатели с древних времен. "Pompilio est nasus cubitis tres longus et unum / Latus, et hunc murus cingit utergut triplex / Absunt et turres, Bacchus guas condidit ipse / Et minio tinctas usgue rubere dedit” («У Помпилия нос длиной в три локтя и в один локоть шириной / И две тройные стены обрамляют его / Есть и башни, которые сам Вакх построил / И окрасил их вдоль красной киноварью» (перевод А.С. Смирновой). Эта эпиграмма опубликована в юмористическом сборнике, датированном 1819 г., а позже процитирована F. Hebra в книге «Руководство к изучению болезней кожи» [3-5]. В знаменитом сатирическом романе фрранцузского писателя XVI Франсуа Рабле «Гаргантюа́ и Пантагрюэ́ль», посвященному в том числе человеческим порокам, краснеющий нос - есть расплата за неумеренное пьянство: «Смотрите за своей рукой: ее так и тянет к вину, оттого у вас нос краснеет». W. Saliceto называл красный нос buzicagua или aura cervina, что переводится как «винная бочка» и «вьючная лошадь для бурдюков» соответственно [3]. Английский священнослужитель, писатель и ученый R. Burton в своем труде «Анатомия меланхолии» также указывал на связь «красноты лица» с алиментарными фракторами, в особенности у людей, склонных к меланхолии [6]. Отражение клиники розацеа можно также найти в произведениях Уильяма Шекспира, в работах великих живописцев (Рембрандта, Доменико Гирландайо) [3].

В истории розацеа можно встретить не только красочные иллюстрации, но и описания с точки зрения медицины, варианты классификаций, многочисленные попытки лечения. Считается, что первым клинику розацеа описал Gue de Chauliac, поэтично называя заболевание gutterose («розовая капля»), также использовался термин Pustule de vin («винные прыщи»), он же советовал кровопускание, применение пиявок и нарывных средств в качестве лечения [2, 3, 5].

N. Florentinus, A. Pare, Astruc различали виды этого страдания: красноту кожи лица, расширение сосудов, наличие воспалительных элементов, в том числе пустулезных, что в той или иной степени является прообразом современных классификаций розацеа $[3,6]$.

J. Darier в первой половине XX в. предположил в патогенезе розацеа сочетание первичного сосудистого расстройства кожи (эритроз) и заболевания эпидермиса, сопровождаемого себореей (kerosis), предложил термин couperose, который до сих пор широко используется в медицине [3].

«...Это уже не живопись, а пластика, уродующая нос, который под влиянием извращенного творчества принимает вид груши», - так F. Hebra описывал ринофриму. A Senertus упоминал о господине, решившем отрезать часть своего носа, мешающую ему при чтении $[3,5]$.
Покровительницей больных розацеа считают Деву Марию, согласно описанию ее жития в гробу вместо ее тела лежал букет алых роз [5].

Согласно статистике, наибольшая заболеваемость розацеа наблюдается среди представителей индоевропейских народов. Самая высокая фиксируется в США (более 16 млн больных) и странах Европы. Наибольший риск развития розацеа имеют лица с I и II фрототипом кожи по Фицпатрику, в то время как лица азиатского и африканского происхождения реже подвержены данному заболеванию [2, 7-9]. Таким образом, отмечается корреляция между риском заболевания и степенью «меланиновой» защиты кожи. Самая высокая заболеваемость розацеа отмечается в Северной Европе (Швеция, Дания, Финляндия, Эстония), недаром исторически заболевание именовалось «приливами кельтов» [2, 7, 9]. Кроме употребления алкоголя в качестве триггерного фактора стоит рассматривать характер пищевого поведения любителей острого и пряностей («синдром китайских ресторанов»).

В развитии воспалительной реакции при розацеа ключевое значение имеют TLR2-рецепторы (компонент врожденного иммунитета кожи), благодаря которым запускается синтез молекул кателицидина, калликреина, матриксных металлопротеиназ, активных фрорм кислорода, окиси азота, цитокинов и хемокинов. В свою очередь, вазоактивные пептиды пищеварительного тракта (VIP; пентагастрин), простагландин E2, медиаторные вещества (эндорфины, брадикинин, серотонин, гистамин, субстанция Р), компоненты калликреин-кининовой системы и токсины влияют на тонус сосудов, повышая проницаемость капилляров и вызывая приливы [2, 10-12].

На современном этапе принято считать, что Demodex folliculorum первостепенного значения в патогенезе розацеа не имеет, однако антигенные белки Bacillus oleronius, которые были выделены у пациентов в ассоциации с клещами Demodex, стимулируют воспалительный ответ у пациентов с папуло-пустулезной розацеа [2, 3, 7].

По данным многих авторов, женщины страдают розацеа в 1,5-2 раза чаще мужчин, однако фриматозную форму заболевания, как правило, регистрируют у последних [2, 7]. Возможно, высокая частота обращений к врачу у женщин связана с более трепетным их отношением к собственному внешнему виду.

\section{Описание клинического случая}

Больной Д. 1990 г. рождения обратился на амбулаторный прием с жалобами на зудящие высыпания. Болен в течение 3 лет, когда впервые отметил периодическое появление высыпаний на коже носа и лба, покраснение кожи лица на фоне психоэмоционального напряжения, занятий спортом. Позднее стал отмечать «приливы» крови к лицу после употребления в пищу острого, сладкого и приема алкоголя (в его служебные обязанности диакона входит «потребление Святых Даров» после литургии). На данном этапе к врачу не обращался, самостоятельно использовал топический стероид с антибиотиком с временным эффектом. Через полгода от начала заболевания обратился к дерматологу по поводу диагноза «демодекоз», назначен метронидазол системно и наружно, эффрект незначительный. Через 2 месяца к лечению уже другим специалистом добавлен доксициклин и витамин А, назначен косметический уход и диета с исклю- 
чением молочных продуктов и сладкого. Значительного улучшения не отметил. Спустя месяц после данного лечения обратился к гомеопату, которым было рекомендовано сыроедение, периодическое лечебное голодание и всевозможные «чистки кишечника, сосудов, печени», дегельминтизация без конкретного диагноза. Во время соблюдения данных рекомендаций за 3 недели похудел на 10 кг, улучшения клинической картины были неявные. Обследован у гастроэнтеролога, по данным фриброгастродуоденоскопии (ФГДС): недостаточность кардии 1-й степени, хронический неатрофический гастрит. Рекомендована диета и консультация ревматолога для исключения системной красной волчанки. Неоднократно обращался за помощью к косметологам с диагнозами «себорейный дерматит», «вульгарные акне», «демодекоз», регулярно получал терапию: системную антибиотикотерапию (тетрациклины, макролиды, имидазолы), топические кортикостероиды, противогрибковые кремы и шампуни, средства с салициловой и азелаиновой кислотами, крем с содержанием метронидазола, УФО. На фроне терапии отмечал отсутствие положительной динамики, а иногда и ухудшение клинической картины (рис. 1, 2).

Семейный анамнез: у младшего брата наблюдается эпизодическое покраснение лица на фроне алиментарных триггеров.

Объективный осмотр: состояние удовлетворительное, температура тела $36,5^{\circ} \mathrm{C}$. Миндалины не увеличены, язык чистый, дыхание везикулярное, хрипов нет, чДД - 18. Хронические заболевания и аллергические реакции отрицает. Другой патологии внутренних органов не выявлено.

Локальный статус от 15.10.2020: патологический кожный процесс ограниченный, островоспалительно-

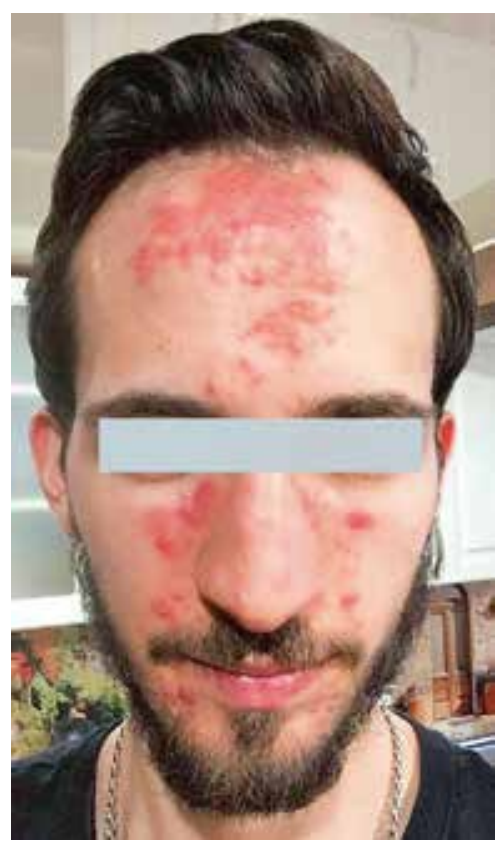

\footnotetext{
Рис. 1. Ухудшение клинической картины после использования топических ГКС (фото предоставлено пациентом)

Fig. 1. The worsening of the clinical picture after use of topical corticosteroids (photo courtesy of the patient)
}

го характера. На коже лица, преимущественно в центральной части, наблюдаются очаги яркой гиперемии, местами с шелушением и инфильтрацией, множественные перифолликулярные папуло-пустулезные элементы, телеангиэктазии. Комедонов нет (рис. 3).

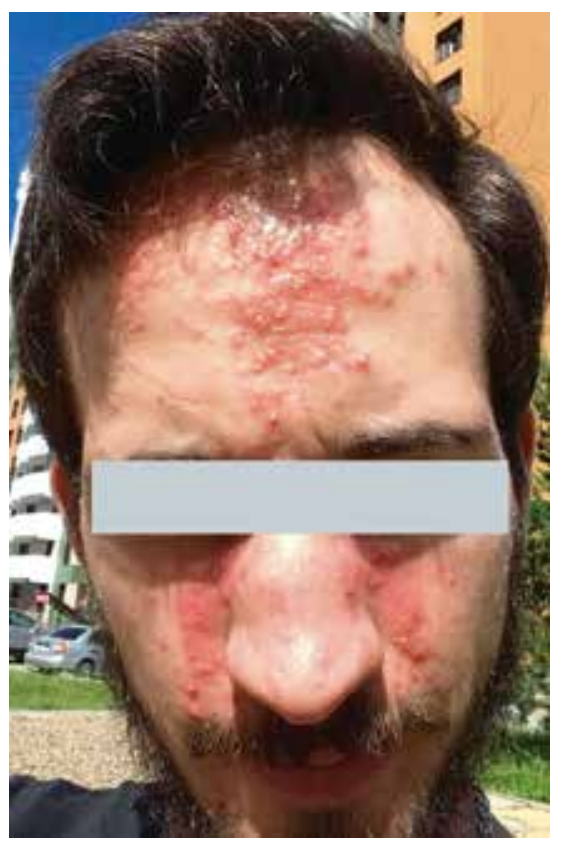

Рис. 2. Ухудшение клинической картины на фоне применения топических ГКС с салициловой кислотой в Комбинации с УФО (фото предоставлено пациентом)

Fig. 2. Worsening of the clinical picture against the background of the use of topical corticosteriods with salicylic acid in combination with UV (photo courtesy of the patient)

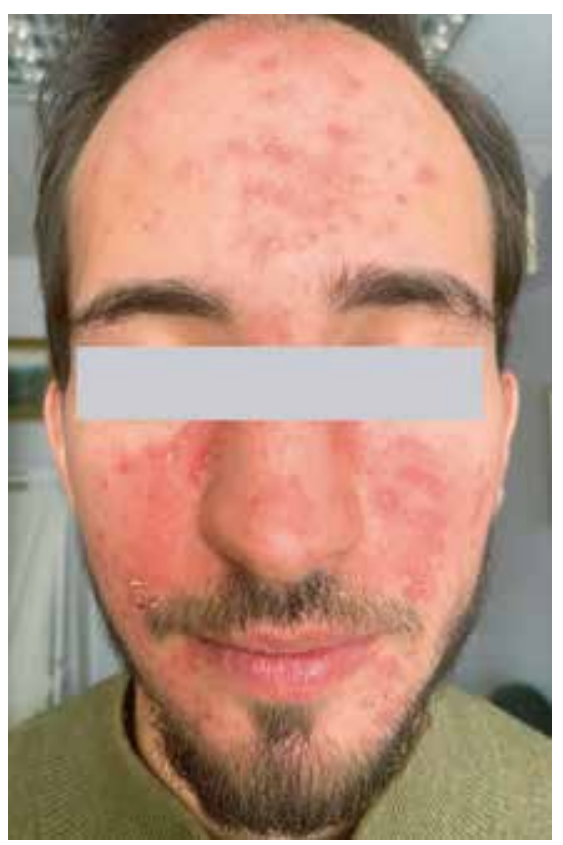

Рис. 3. Очаги гиперемии, шелушение, инфильтрация, множественные пери фолликулярные папуло-пустулезные элементы, телеангиэктазии Fig. 3. Foci of hyperemia, desquamation, infiltration, multiple perifollicular papulopustular elements, telangiectasia 
На основании клинических и анамнестических данных установлен диагноз «розацеа, папуло-пустулезный подтип» (L 71).

Лабораторные исследования: в общем анализе крови, биохимическом анализе крови, общем анализе мочи патологических изменений не выявлено.

Учитывая анамнез пациента, длительность заболевания и резистентность к назначенной ранее терапии, пациенту назначены системные ретиноиды: изотретиноин в суточной дозе 0,3 мг/кг (по 20 мг/сут при массе тела 67 кг) курсом на 6 месяцев с ежемесячным контролем показателей биохимии крови и профилактическим приемом гепатопротекторов (адеметионин по 400 мг/сут в течение 2 нед. каждый месяц при приеме изотретиноина). Наружно назначены эмоленты, средства с солнцезащитными фильтрами.

Для оценки степени влияния заболевания было использовано тестирование с помощью опросника «Дерматологического индекса качества жизни» (DLQI) [13]. В начале терапии результат составил 19 баллов, что интерпретируется как сильное влияние.

На фоне терапии пациент отметил улучшение в течение первого месяца, уменьшение количества воспалительных элементов на коже, снижение зуда и выраженности гиперемии (рис. 4). Из побочных эффректов отмечал незначительную сухость слизистых оболочек, что корректировалось назначением симптоматической терапии (увлажняющие назальные капли).

На момент написания статьи пациент заканчивает курс изотретиноина. При осмотре: патологический кожный процесс разрешился, отмечается умеренная сухость кожных покровов, высыпаний нет, сохраняются единичные телеангиэктазии (рис. 5). Проведено повторное тестирование DLQI, и его результат снизился до 2 баллов (незначительное влияние): у пациента отмечается только покраснение лица во время интенсивных занятий спортом и некоторый дискомфорт от терапии (сухость кожи и слизистых оболочек).

После окончания терапии пациенту рекомендован охранительный режим, по возможности - избегание ситуаций, сопровождающихся резким приливом крови к лицу, периодический прием сосудоукрепляющих препаратов, рекомендации по питанию и дальнейшему уходу за кожей лица.

\section{Обсуждение}

Представление о розацеа как о мультифакториальном дерматозе подразумевает огромное количество триггерных фракторов. В данном случае можно констатировать, что возникла комбинация триггеров (стресс, занятия спортом, алиментарные фракторы, сопутствующие соматические заболевания) на фоне семейного анамнеза заболевания и была назначена терапия, которая на протяжении нескольких лет усугубляла течение заболевания. Диагнозы, по поводу которых пациент получал терапию ранее, традиционно рассматриваются в качестве диффреренциальной диагностики розацеа.

Для себорейного дерматита действительно характерны эритематозные очаги с умеренным шелушением и расположением в центрофациальной области, сопровождающиеся зудом, однако следует помнить, что при этом должны наблюдаться себорея и комедоны вместо телеангиэктазий.

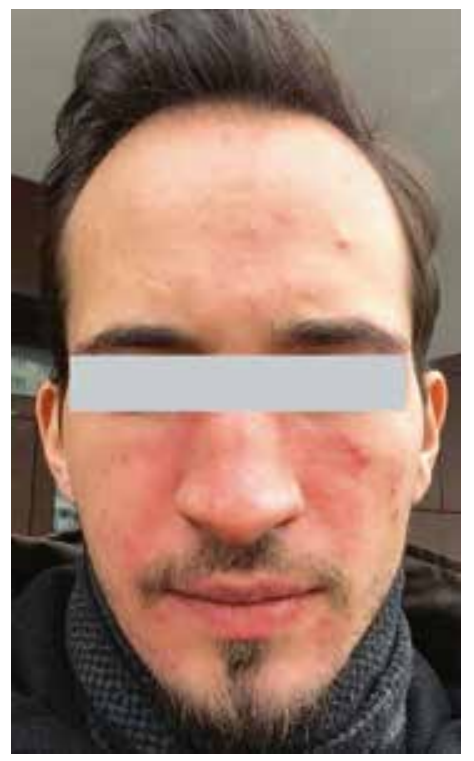

Рис. 4. Уменьшение количества воспалительных элементов и гиперемии (фото предоставлено пациентом)

Fig. 4. Reducing the amount of inflammatory elements and hyperemia (photo courtesy of the patient)

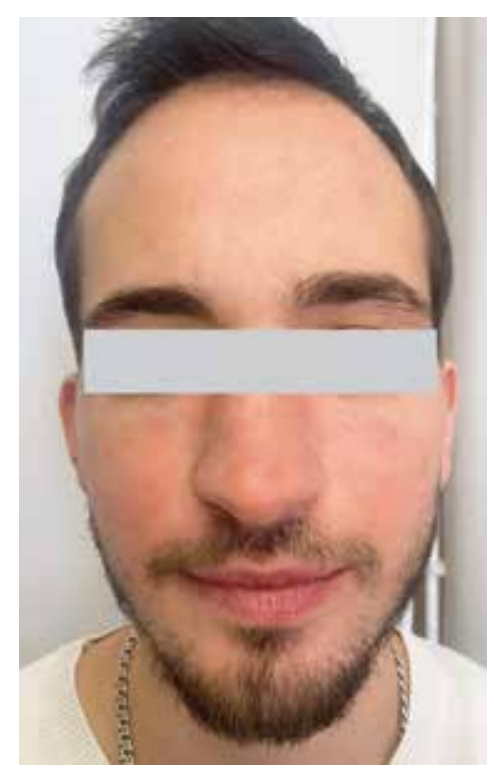

Рис. 5. Умеренная сухость кожи, отсутствие высыпаний, единичные телеангиэктазии

Fig. 5. Mild dry skin, absence of rash, isolated telangiectasia

Вульгарные акне, как правило, дебютируют в пубертатном возрасте, в процесс зачастую вовлекается кожа груди и спины, и также сопровождаются явлениями себореи, а сосудистые звездочки могут быть результатом местной раздражающей терапии.

Диагноз «демодекоз» в настоящее время не актуален, в современных клинических рекомендациях микроскопическое исследование кожи с целью обнаружения клещей-железниц не предусмотрено $[1,10]$. 


\section{Заключение}

Несмотря на достигнутый успех терапии не следует забывать о возможных рецидивах и необходимости минимизировать раздражающие фракторы.

В основу терапии розацеа должно входить не только медикаментозное лечение для снятия обострения кожного процесса, но и формирование ряда правил и привычек, способствующих продлению ремиссии и повышению качества жизни, в том числе элиминация стрессовых ситуаций, чрезмерной инсоляции, ограничение алиментарных триггеров (острое, пряности, алкоголь), использование адекватных средств для ухода за кожей, а также проведение наружной противорецидивной, профилактической терапии после окончания основного курса лечения.

\section{Литература/References}

1. Федеральные клинические рекомендации. Дерматовенерология, 2015: Болезни кожи. Инфекции, передаваемые половым путем. М.: Деловой экспресс, 2016. [Federal clinical guidelines. Dermatovenereology, 2015: Diseases of the skin. Sexually transmitted infections. Moscow: Delovoy ekspress; 2016 (In Russ.)]

2. Кубанова А.А., Махакова Ю.Б. Розацеа: распространенность, патогенез, особенности клинических проявлений. Вестник дерматологии и венерологии. 2015;(3):36-45. [Kubanova AA, Makhakova YuB. Rosacea: prevalence, pathogenesis, particular features of clinical manifestations. Vestnik Dermatologii i Venerologii. 2015;(3):36-45 (In Russ.)]

3. Заславский Д.В., Егорова Ю.С., Оловянишников О.В., Волкова Н.С. $\mathrm{K}$ вопросу об истории и комплексном лечении розацеа. Клиническая дерматология и венерология. 2009;7(3):80-84. [Zaslavskiy DV, Egorova luS, Olovianishnikov OV, Volkova NS. On the history and combined therapy of rosacea. Clinical Dermatology and Venereology. 2009;7(3):80-84 (In Russ.)]

4. Becher FL. Witzfunken und Lichtleiter, oder neue geordnete Auswahl von Gegenständen des Scherzes, der Laune, des Witzes und Scharfsinns. Cnobloch. 1819. P. 216.

5. Гебра Ф. Руководство к изучению болезней кожи. Под ред. А. Полотебнова. СПб: Изд-во О.И. Бакста, 1876. с. 781. [Hebra F. A guide to the study of skin diseases. Ed. by A. Polotebnov. SPB: Publ. 0.I. Bakst. 1876. P. 781 (In Russ.)]

6. Eastwood SR. Gastric secretion and other digestive factors in rosacea. The british journal of dermatology and syphilis. 1928;40:91-104.

7. Жильцова Е.Е., Межевая К.В., Исаков С.А. Современные аспекты распространенности и клиники розацеа. Лечащий врач. 2019;(9):82-82. [Zhiltsova EE, Mezhevaya KV, Isakov SA. Modern aspects of the prevalence and clinical picture of rosacea. Lechaschiy vrach. 2019;(9):80-82 (In Russ.)]
8. Two AM, Del Rosso JQ. Kallikrein 5-mediated inflammation in rosacea: clinically relevant correlations with acute and chronic manifestations in rosacea and how individual treatments may provide therapeutic benefit. J Clin Aesthet Dermatol. 2014;7(1):20-25.

9. Abram K, Silm H, Maaroos HI, Oona M. Risk factors associated with rosacea. J Eur Acad Dermatol Venereol. 2010;24(5):565-571.

doi: 10.1111/j.1468-3083.2009.03472.x

10. Рябова В.В., Кошкин С.В., Чермных Т.В. Розацеа. Себорея. Угревая болезнь. Иллюстрированное учебное пособие для врачей. Киров: Кировская ГMA, 2011. [Ryabova VV, Koshkin SV, Tchermnykh TV. Rosacea. Seborrhea. Acne disease. Illustrated textbook for doctors. Kirov: Kirov SMA. 2011 (In Russ.)]

11. Савоськина В.А., Бильченко А.А. Розацеа: особенности патофизиологии, клиники и лечения. Клиническая иммунология. Аллергология. Инфектология. 2012;8(57):5-13. [Savoskina VA, Bilchenko AA. Rosacea: features of pathophysiology, clinical picture and treatment. Clinical immunology. Allergology. Infectology. 2012;8(57):5-13 (In Russ.)]

12. Чеботарев В.В., Асхаков М.С., Одинец А.В., Чеботарева Н.В. Руководство для клинических ординаторов по дерматовенерологии в двух томах (Том I). Под ред. В.В. Чеботарева. Ставрополь: СтГМУ. 2020. 393 c. [Chebotarev VV, Askhakov MS, Odinets AV, Chebotareva NV. A guide for clinical residents in dermatovenereology in two volumes (Vol. 1) Ed. by V.V. Chebotarev. Stavropol: StSMU. 2020. P. 393 (In Russ.)]

13. Finlay AY, Khan GK. Dermatology Life Quality Index (DLQI) a simple practical measure for routine clinical use. Clin Exp Dermatol. 1994;19(3):210-216. doi: 10.1111/j.1365-2230.1994.tb01167.x

Участие авторов: все авторы несут ответственность за содержание и целостность всей статьи. Концепция и дизайн исследования С. В. Кошкин; сбор и обработка материала, написание текста, редактирование - А. Л. Евсеева, В. В. Рябова.

Authors' participation: all authors are responsible for the content and integrity of the entire article. Research concept and design - Sergei V. Koshkin; collection and processing of material, writing and editing text — Anna L. Evseeva, Vera V. Ryabova. 


\section{Информация об авторах}

*Сергей Владимирович Кошкин - д.м.н., профрессор; адрес: Россия, 610027, г. Киров, ул. К. Маркса, д. 112; ORCID iD: https://orcid.org/0000-0002-6220-8304; eLibrary SPIN: 6321-0197; e-mail: koshkin_sergey@mail.ru

Анна Леонидовна Евсеева — ORCID iD: https://orcid.org/0000-0001-6680-283X; eLibrary SPIN: 2409-6034; e-mail: jIs0105@icloud.com

Вера Владимировна Рябова — ассистент; ORCID iD: https://orcid.org/0000-0002-6594-6652; eLibrary SPIN: 5573-6747; e-mail: ryabova.vv@gmail.com

\section{Information about the authors}

*Sergei V. Koshkin — MD, Dr. Sci. (Med.), Professor; address: 112 K. Marx street, 610027, Kirov, Russia; ORCID iD: https://orcid.org/0000-0002-6220-8304; eLibrary SPIN: 6321-0197; e-mail: koshkin_sergey@mail.ru

Anna L. Evseeva — ORCID iD: https://orcid.org/0000-0001-6680-283X; eLibrary SPIN: 2409-6034; e-mail: jls0105@icloud.com

Vera V. Ryabova - assistant lecturer; ORCID iD: https://orcid.org/0000-0002-6594-6652; eLibrary SPIN: 5573-6747; e-mail: ryabova.vv@gmail.com

Статья поступила в редакцию: 07.04.2021

Принята к публикации: 12.05.2021

Дата публикации: 15.06 .2021
Submitted: 07.04.2021

Accepted: 12.05.2021

Published: 15.06 .2021 